\title{
MONITORAMENTO FLUVIOMÉTRICO E PLUVIOMÉTRICO NO RIBEIRÃO MANDAGUARI, NO MUNICIPIO DE PRESIDENTE PRUDENTE - OESTE PAULISTA
}

Plínio Carielo, Renata Pereira Prates, Renato de Araújo Ferreira, João Luiz Dal Ponte Filho, Valentim Vicente Perussi, Rosildo dos Santos, Valdirene de Jesus Timóteo, Francieli de Lima Batista.

Escola Técnica Estadual Prof. Dr. Antonio Eufrásio de Toledo - ETEC, Presidente Prudente, SP. pliniocarielo@hotmail.com

\section{RESUMO}

O objetivo desse trabalho foi caracterizar os aspectos hidrológicos relacionados ao monitoramento fluviométrico e pluviométrico no Ribeirão Mandaguari. A área de estudo está localizada na Bacia Hidrográfica do Rio do Peixe, município de Presidente Prudente (SP). Foram analisados os dados dos postos fluviométricos e pluviométricos, através de série histórica abrangendo os anos de 2000 a 2013. A análise hidrológica, bem como dos dados de precipitação tem como finalidade compreender as dinâmicas fluviais da área de estudo. Os resultados obtidos das análises a partir das estações pluviométricas e fluviométricas possibilitaram compreender o comportamento hidrodinâmico e as possíveis alterações ocorridas no Ribeirão Mandaguari, destacando a periodicidade e magnitude das vazões.

Palavras-chave: análise hidrológica, precipitação, vazão, rio do peixe, ribeirão Mandaguari

\section{MONITORING RUNOFF AND RAINFALL OF RIBEIRÃO MANDAGUARI THE MUNICIPALITY OF PRESIDENTE PRUDENTE - PAULISTA WEST.}

\begin{abstract}
The aim of this study was to characterize the hydrological aspects related to monitoring runoff and rainfall in Ribeirão Mandaguari. The study area is located in the Basin of Peixe River, municipality of Presidente Prudente (SP). The data of streamflow and rainfall stations were analyzed through time series covering the years 2000 to 2013 . The hydrological analysis as well as precipitation data aims to understand the fluvial dynamics of the study area. The results of the analyzes from rainfall and gauged stations made it possible to understand the hydrodynamic behavior and possible changes in the Ribeirão Mandaguari, highlighting the frequency and magnitude of flows.
\end{abstract}

Keywords: analysis hydrology, precipitation, flow rate, River fish, brook mandaguari 


\section{INTRODUÇÃO}

Um dos principais eventos naturais, especialmente nas regiões tropicais é a precipitação. Grande número das atividades humanas estão diretamente relacionadas à gestão dos recursos hídricos, entre elas, a produção de eletricidade e o abastecimento de água, tanto potável, como não potável. Na agricultura, por exemplo, a precipitação é um dos principais fatores que determinam o sucesso ou fracasso no desenvolvimento de determinadas culturas, incluindo nesse processo as atividades de preparação da terra, o plantio, irrigação e a colheita. Além disso, a população urbana tem crescido substancialmente, colocando mais demandas sobre os recursos hídricos disponíveis.

Assim, faz se necessário compreender algumas dinâmicas hídricas, inseridas dentro da bacia hidrográfica. A bacia hidrográfica é a área de terra que faz drenagem das águas de chuvas, para cursos d'águas e rios e destes para outros maiores; esta área da bacia hidrográfica é delimitada pelo divisor de água, que são espigões, serras, picos, montanhas, morros, que separa uma bacia de outra adjacente e pode ser delimitada através das curvas de nível em cartas topográficas.

Estas bacias recebem água na forma de chuva, que é monitorada através de um índice pluviométrico, que tecnicamente chamamos de precipitação, este índice é dado por $\mathrm{mm} / \mathrm{m}^{2}$. Desta precipitação, parte irá se infiltrar no solo abastecendo o lençol freático, que por sua vez irá alimentar as minas que alimentam os rios em tempo de estiagem; outra parte irá sofrer escoamento superficial, provocando cheias nos riachos e rios, e até mesmo assoreamento ao levar sedimentos; e uma parte será voltara para o estado gasoso através da evaporação.

Com o propósito de demonstrar a importância das medições de precipitação e vazão, este trabalho tem como objetivo caracterizar e analisar a partir dos dados fluviométricos e pluviométricos o comportamento hidrodinâmico do Ribeirão Mandaguari, na região oeste do Estado de São Paulo.

\section{METODOLOGIA}

Área de Estudo

O Ribeirão Mandaguari é composto por diferentes córregos que tem suas nascentes localizadas em diferentes municípios da região de Presidente Prudente - SP; Martinópolis, Regente Feijó, Indiana, Presidente Prudente, Caiabú e Alfredo Marcondes. Da cabeceira até a foz em linha reta, sem analisar as tortuosidades, possui aproximadamente 35 quilômetros de 
comprimento. A foz ocorre no Rio do Peixe próximo a captação de água da SABESP (Companhia de Saneamento Básico do Estado de São Paulo) para o município de Presidente Prudente - SP.

A microbacia Ribeirão Mandaguari drena uma área de $700 \mathrm{Km}^{2}$ e integra a bacia hidrográfica do Rio do Peixe, oeste do Estado de São Paulo.

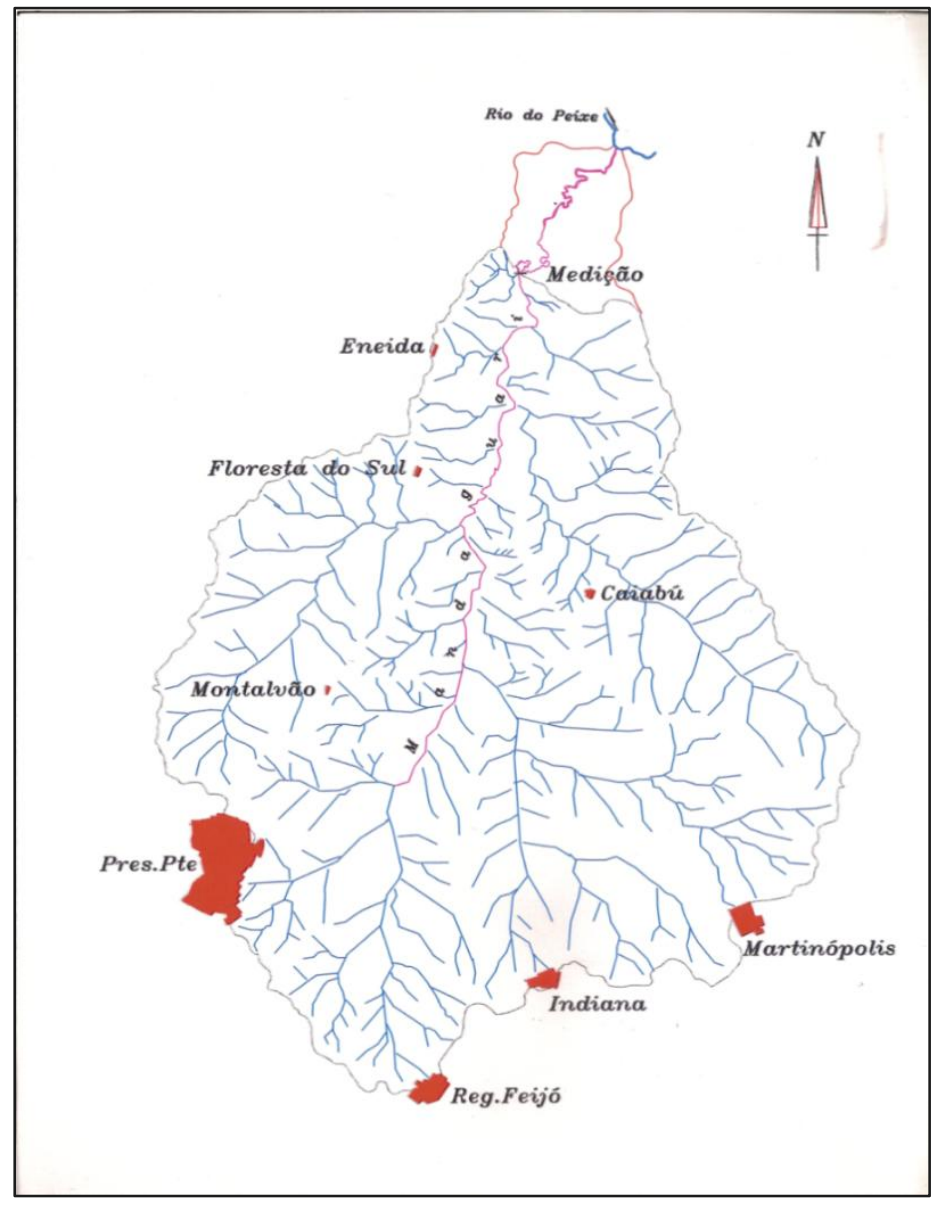

Figura 1. Localização da área de estudo - Ribeirão Mandaguari.

A região é constituída por rochas vulcânicas e sedimentares da Bacia do Paraná, do período mesozóico e depósitos aluvionares de idade cenozóica e pertence ao Planalto Centro Ocidental, de acordo com Mapa Geomorfológico do Estado de São Paulo em escala 1: 1.000.000 (IPT, 1981b), com predomínio de colinas amplas e baixas com topos aplainados e, Planícies Fluviais que ocorrem nos vales com preenchimento aluvial.

Segundo Monteiro (1973), a região sudoeste do Estado de São Paulo, situa-se em uma zona de transição climática onde a circulação atmosférica é controlada pela dinâmica das massas tropicais, setentrionais e meridionais. Destas massas de ar, observa-se que a frente polar Atlântica é responsável pela produção de maior quantidade de precipitação na região. 


\section{Procedimentos Metodológicos}

Os dados fluviométricos e pluviométricos foram obtidos dos sítios eletrônicos do Departamento Estadual de Águas de São Paulo (SIGRH) e Agência Nacional de Águas (ANA). Assim como as séries de dados pluviométricos do Ribeirão Mandaguari, apresentavam algumas falhas de dados, estas foram preenchidas partir do coeficiente de determinação $\left(R^{2}>0,7\right)$ através de regressão linear, conforme preconizado por Poff et al. (1997) e Rocha (2002). Para a correlação de informações foram utilizados os dados do posto vizinho, cuja série de dados é mais longa e apresenta menor quantidade de falhas.

Para medir a vazão é necessário três parâmetros: largura, profundidade e velocidade. Vazão $(Q)=$ Velocidade $(\mathrm{m} / \mathrm{sg})$ X área de seção $\left(\mathrm{m}^{2}\right)$ onde $Q=\mathrm{m}^{3} / \mathrm{s}$ ou $Q=\mathrm{l} / \mathrm{s}$.

\section{RESULTADOS}

Com os dados coletados foi possível observar uma mudança significativa na área da seção monitorada, conforme comparação do levantamento do perfil das margens realizado em 2005, apresentando 3,90 $\mathrm{m}^{2}$, enquanto que em 2015 o dado da mensuração foi de $6,99 \mathrm{~m}^{2}$, como podem ser observados nas Figuras 2 e 3.

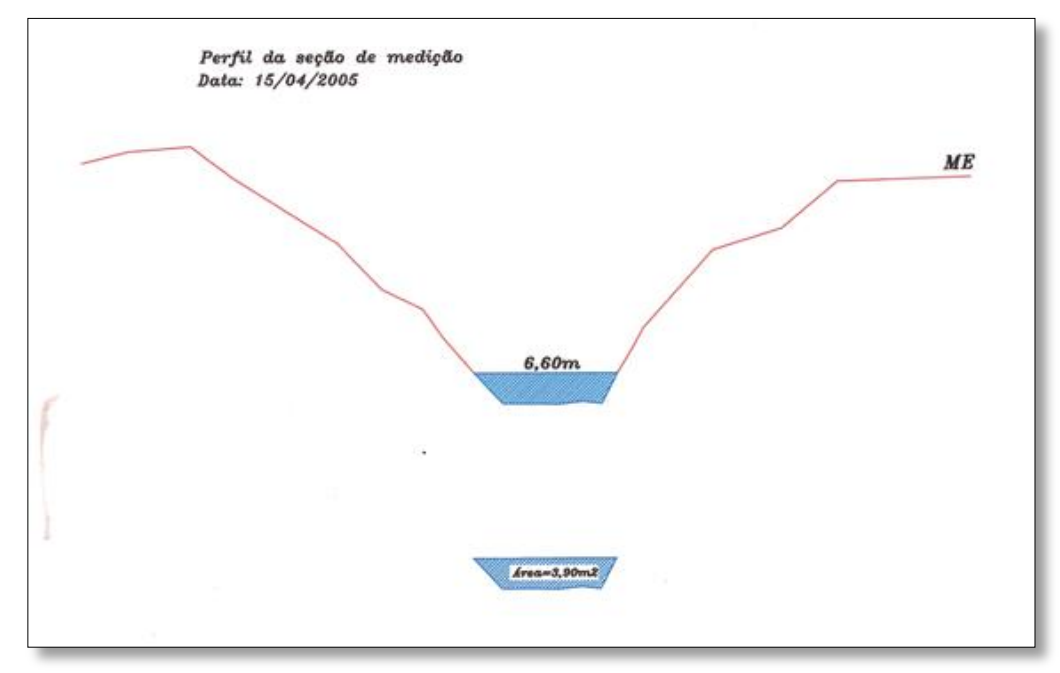

Figura 2. Perfil da seção de medição 2005. Fonte DAEE, 2005. 


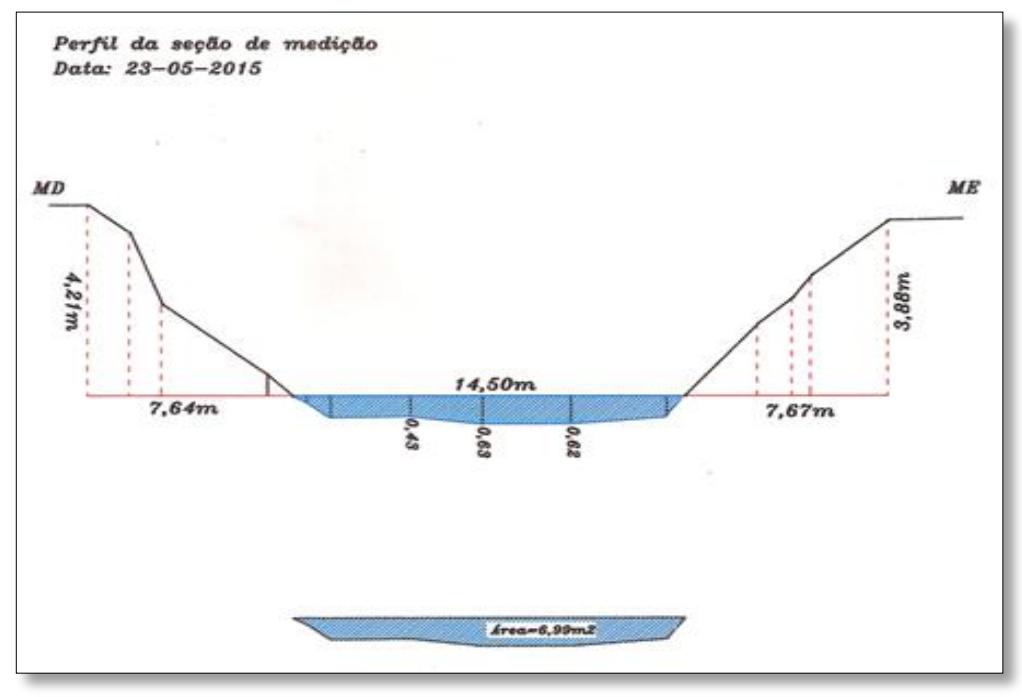

Figura 3. Perfil da seção de medição em maio de 2015

$\mathrm{Na}$ tabela 1 os dados apresentados referem-se às medições fluviométricas do posto 8C007, localizado no Ribeirão Mandaguari no Município de Presidente Prudente, para os anos de 2000 a 2013. 
Tabela 1. Dados das vazões médias mensais e anuais, Posto Fluviométricos Posto 8C-007 - Ribeirão Mandaguari (SP)

\begin{tabular}{|c|c|c|c|c|c|c|c|c|c|c|c|c|c|}
\hline Ano & Jan. & Fev. & Março & Abril & Maio & Jun & Jul & Ago & Set & Out & Nov & Dez & Média \\
\hline 2000 & 3,36 & 17,75 & 18,42 & 2,95 & 2,07 & 1,95 & 2,74 & 2,33 & 8,15 & 2,5 & 3,28 & 2,88 & 5,7 \\
\hline 2001 & 1,93 & 14,66 & 7,67 & 3,17 & 5,0 & 3,31 & 2,62 & 2,12 & 2,11 & 2,94 & 3,59 & 6,27 & 4,6 \\
\hline 2002 & 9,26 & 4,41 & 3,0 & 1,88 & 4,67 & 2,9 & 3,0 & 3,14 & 3,23 & 2,29 & 4,34 & 9,85 & 4,3 \\
\hline 2003 & 25,96 & 16,11 & 8,74 & 7,4 & 4,63 & 5,54 & 3,81 & 3,92 & 4,04 & 3,53 & 3,5 & 3,78 & 7,5 \\
\hline 2004 & 4,87 & 4,43 & 8,2 & 2,98 & 5,66 & 4,78 & 4,47 & 2,62 & 2,32 & 5,14 & 6012 & 4,02 & 4,6 \\
\hline 2005 & 12,22 & 3,93 & 2,69 & 3,18 & 3,6 & 3,69 & 2,4 & 2,03 & 3,84 & 4,44 & 2,32 & 2,96 & 3,9 \\
\hline 2006 & 5,0 & 13,0 & 10,19 & 3,61 & 2,64 & 1,95 & 2,05 & 1,9 & 2,29 & 3,02 & 1,89 & 6,44 & 4,5 \\
\hline 2007 & 30,84 & 12,09 & 5,24 & 3,17 & 3,28 & 2,69 & 8,3 & 2,94 & 2,09 & 2,23 & 3,86 & 2,33 & 6,5 \\
\hline 2008 & 4,97 & 4,88 & 5,8 & 3,58 & 4,4 & 2,34 & 1,88 & 2,56 & 1,71 & 2,39 & 2,45 & 1,71 & 3,2 \\
\hline 2009 & 26,68 & 12,13 & 4,91 & 2,55 & 2,89 & 3,12 & 4,53 & 7,63 & 6,44 & 12,01 & 7,16 & 21,59 & 9,3 \\
\hline 2010 & 42,84 & - & - & - & - & 4,3 & 3,95 & 3,03 & 7,27 & 4,47 & 3,5 & 4,37 & 9,2 \\
\hline 2011 & 9,53 & 16,38 & 11,94 & 6,88 & 4,55 & 4,89 & 4,28 & 4,64 & 3,36 & 5,41 & 5,14 & 5,33 & 6,8 \\
\hline 2012 & 9,13 & 4,08 & 5,98 & 4,09 & 5,87 & 16,35 & 5,3 & 3,05 & 6,1 & 3,74 & 6,63 & 11,21 & 6,7 \\
\hline 2013 & 9,25 & 10,18 & 8,73 & 14,08 & 9,7 & 10,44 & 6,18 & 4,51 & 5,52 & 8,31 & 7,02 & 5,16 & 8,2 \\
\hline
\end{tabular}

Fonte: Departamento de Águas e Energia Elétrica - DAEE - Pluviometria - Site: http://www.hidrologia.daee.sp.gov.br/. Acesso em: 20 de Maio de 2015. 


\section{DISCUSSÃO}

Analisando os dados fluviométricos foi possível determinar a vazão média para o período analisado, verificando-se que os picos de vazão que ocorreram. Em seguida os dados foram comparados a partir da elaboração de gráfico, com o objetivo de compreender a quantidade de água existente no curso d'água, conforme a Figura 4.

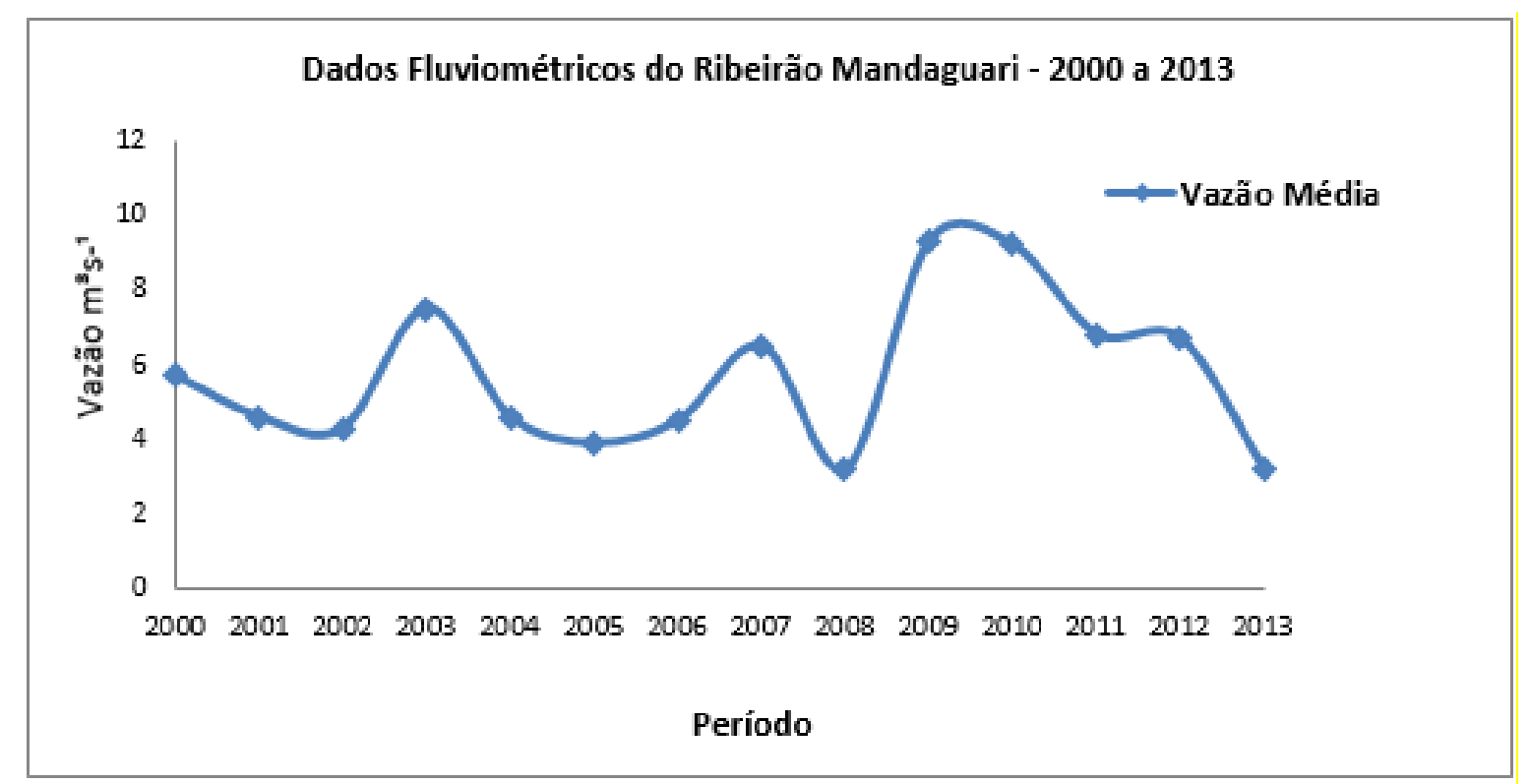

Figura 4. Dados Fluviométricos da Bacia do Ribeirão Mandaguari - Período: 2000 a 2013.

Os dados fluviométricos do Ribeirão Mandaguari, apresentados na Figura 4, indicam que os maiores valores de vazão registrados ocorreram durantes os anos de 2003, 2007, 2009, 2010 e 2013. Os dados pluviométricos determinam os valores médios de água que entraram na microbacia do Ribeirão Mandaguari, dados estes que podem auxiliar no planejamento ambiental e rural e para a gestão dos recursos hídricos, além de compreender o comportamento do sistema hidrológico do rio, bem como as possíveis alterações ocorridas em relação à magnitude dos índices fluviométricos na área de estudo.

As dinâmicas dos processos hidrológicos no Ribeirão Mandaguari podem ser observadas na Figura 5, na qual foi utilizada a série de dados disponível para a estação pluviométrica estudada, apresentando assim baixa variabilidade ao longo da série. 


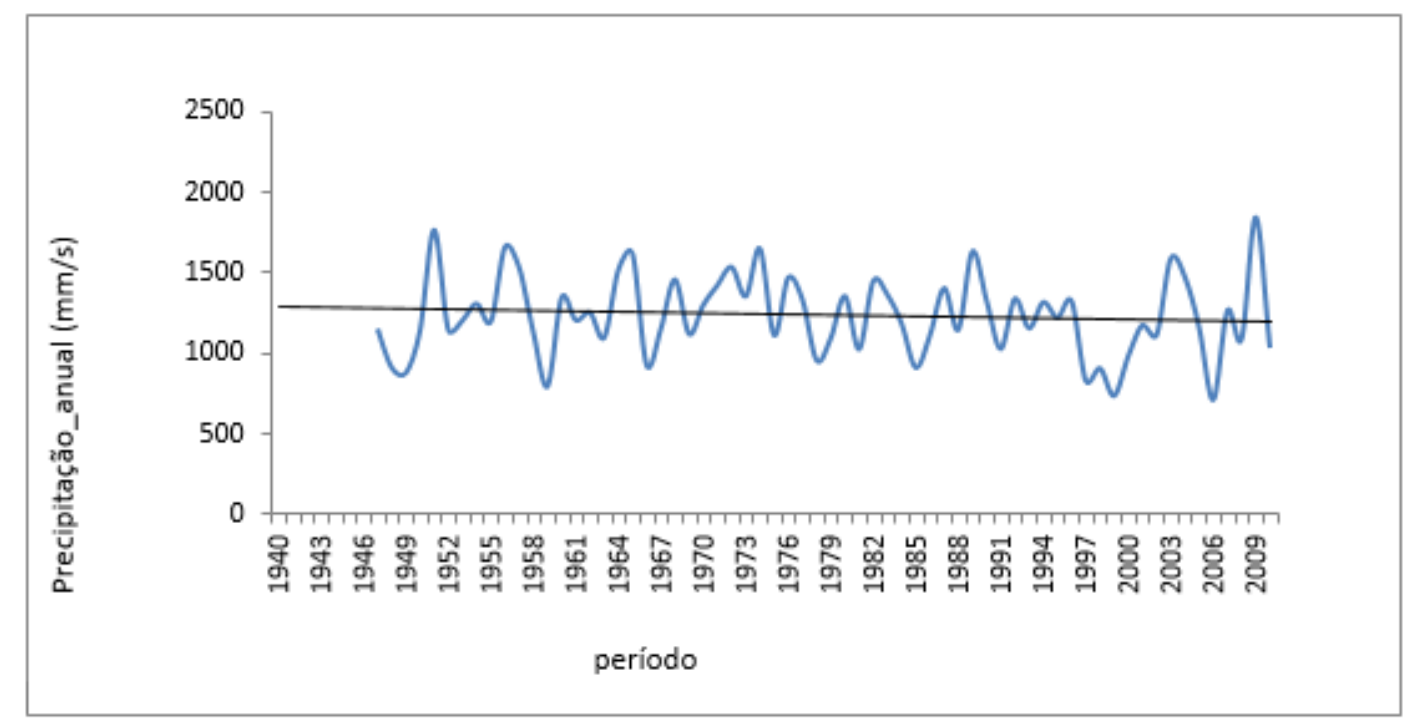

Figura 5. Dados Fluviométricos da Bacia do Ribeirão Mandaguari - Período: 2000 a 2013. Fonte: Arquivo Pessoal, 2015.

Sant'Anna Neto (2000) observou que os valores de pluviosidade mensal em série histórica para Presidente Prudente, no Oeste Paulista, demonstram pequena alteração na sazonalidade das chuvas, no qual é possível perceber que o verão foi se tornando mais úmido, enquanto que o mês mais chuvoso se deslocou de dezembro-janeiro, para fevereiro-março durante as décadas.

O desenvolvimento econômico, o aumento da população, a diversificação, o consumo, o crescimento das cidades, as atividades industriais e a agricultura tem acelerado os processos de degradação da natureza, especialmente os recursos hídricos.

As intervenções antrópicas atuam, principalmente, no âmbito da cobertura vegetal e do uso da terra e podem repercutir em outras variáveis do sistema, primordialmente a alteração dos padrões físicos e químicos dos escoamentos e, potencialmente, nas variáveis climáticas, dentro de uma escala mais restrita, tal como uma pequena bacia hidrográfica.

\section{CONCLUSÃO}

A série histórica da estação pluviométrica e fluviométrica analisada possibilitou compreender o comportamento hidrodinâmico do Ribeirão Mandaguari, destacando a periodicidade e magnitude das vazões durante o período avaliado.

Grande parte das atividades humanas está diretamente relacionada à gestão dos recursos hídricos, como, a produção de eletricidade e abastecimento de água, tanto potável, como não potável. Assim, observa-se que as intervenções antrópicas e a apropriação dos recursos hídricos pelo homem podem provocar diversos impactos no regime hidrológico do rio. Deste modo, existe 
uma necessidade de se compreender e predizer os impactos ecológicos que podem ocorrer no sistema hidrológico.

\section{REFERÊNCIAS}

Christofoletti, A., 1974. Geomorfologia. Ed. Edgard Blucher Ltda e EDUSP.

KIPPER, J.; CHAMBÓ, E.D.; STEFANELLO, S.; GARCIA, R.C. levantamento florístico de um componente arbóreo de mata ciliar do Rio Paraná, Marechal Cândido Rondon, PR. Revista Scientia Agraria Paranaensis. Volume 9, número 1 - 2010, p. 82- 92.

POFF, H L; ALLAN, D; BAIN, M B; KARR, J R; PRESTEGAARD, K L; RICHTEr, B D; SPARKS, R E; STROMBERG, J C. (1997) The natural flow regime: a paradigm for river conservation and restoration. Bioscience, 769-784. http://dx.doi.org/10.2307/1313099

ROCHA, P. C. Dinâmica dos canais no sistema rio-planície fluvial do alto rio Paraná, nas proximidades de Porto Rico-PR. 2002. 171 f. Tese (Doutorado em Ecologia de Ambientes Aquáticos Continentais) - Universidade Estadual de Maringá, Maringá.

SOUZA, A. de; ARAÚJO, R. R. de; ARROIO JR, P. P; LEAL, A. C. Situação atual da mata ciliar de um trecho do rio Santo Anastácio, SP. Revista Tópos, v. 5, n. 2, p. 182-197, 2011.

TUCCI, C.; E. M. Regionalização de vazões. Rio Grande do Sul: Ed. Universidade/UFRGS, 2002.

VILLELA, S. M. E MATTOS, A. 1975, Hidrologia Aplicada. Editora Mc Graw Hill, São Paulo 245p. 